\title{
Quem conta um conto aumenta um ponto: práticas de retextualização como incentivo à produção de textos multissemióticos
}

\author{
Who tells a tale increases a point: retextualization practices \\ as an incentive to the production of multisemiotic texts
}

\author{
Helena Maria Ferreira \\ Universidade Federal de Lavras \\ Marco Antonio Villarta-Neder \\ Universidade Federal de Lavras \\ Geanne dos Santos Cabral Coe \\ Universidade Federal de Lavras
}

DOI: https://doi.org/10.5902/2176148535399

Resumo: Este trabalho discute possibilidades teórico-metodológicas trazidas pelos recursos tecnológicos para o trabalho com a produção de textos multissemióticos em sala de aula, a partir de uma pesquisa teórica que evidencia a questão dos multiletramentos e a constituição dos sujeitos. Para ilustrar a discussão, o trabalho apresenta um relato de pesquisa sobre uma experiência de retextualização de um conto com uso de gifs. Os resultados evidenciam que as dimensões epistemológicas e axiológicas apresentadas pelos autores estudados, se assumidas pelos professores, podem trazer avanços substanciais para a ressignificação de metodologias voltadas para a produção de textos em múltiplos contextos.

Palavra-chave: Produção de texto. Multimodalidade. Multissemiose. Formação de professores

Abstract: This work discusses the theoretical-methodological possibilities brought by the technological resources for the work with the production of multisemiotic texts in the classroom, based on a theoretical research that highlights the question of multiletramentos and the constitution of the subjects. To illustrate the discussion, the paper presents a research report about a retextualization experience of a story using gifs. The results demonstrate that the epistemological and axiological dimensions presented by the authors studied, if assumed by the teachers, can bring substantial advances to the re-signification of methodologies aimed at the production of texts in multiple contexts. Keyword: Text production. Multisemiosis. Teacher education. 


\section{INTRODUÇÃo}

A fim de interagir com variados interlocutores, o homem produz enun-

Helena Maria

Ferreira

Marco Antonio

Villarta-Neder

Geanne dos

Santos Cabral

Coe ciados, que apresentam uma determinada função social, uma forma composicional, uma organização linguístico-semiótico-discursiva e um conteúdo temático, especificidades que os caracterizam como gêneros discursivos e enredam diferentes usos da linguagem. Nesse contexto, diferentes modos/recursos podem ser mobilizados no processo de produção, uma vez que os enunciados podem tanto apresentar linguagem/semiose verbal-escrita (sistema semiótico linguístico) quanto linguagens visuais-sonoras (sistema semiótico visual e sonoro), isto é, linguagens híbridas. Sendo assim, diante de tanta variedade possível na produção de textos, principalmente, com o avanço da tecnologia, as palavras saem de suportes como o papel e ocupam espaços variados, abrindo outras possibilidades mais atraentes para se dizer o que se pretende dizer.

Entretanto, apesar das diversas possibilidades de se construir um texto, no ambiente escolar da educação básica, o que se observa com frequência é que se explora, quase que de modo exclusivo, a produção de textos como treino em papel e lápis/caneta. Essas produções, recorrentemente, apresentam propósitos pedagógicos para execução de alguma proposta curricular, preparação para processos seletivos e/ou ocupação do tempo escolar, o que acaba por inviabilizar um trabalho voltado para os multiletramentos.

É fato que os processos seletivos para ingresso no ensino superior demandam um investimento pedagógico diferenciado, em face das exigências da sociedade, no entanto, o excesso de "treinamento" fornecido pelas escolas tem desencadeado um trabalho com o texto, e não com gêneros discursivos, enquanto articulações de práticas sociais e práticas de linguagem. Ao assumir essa perspectiva de trabalho, a escola impede o aluno de refletir sobre os diferentes gêneros existentes na sociedade, e, consequentemente, de participar ativamente de diferentes situações sociais, de contextos de usos reais da língua. Segundo Pimenta e Santana (2007, p. 152), a sociedade está mudando e é muito importante provocar transformações nas produções textuais. Para as autoras,

até recentemente, a pedagogia do letramento era um projeto cuidadosamente restrito; restrito a formas de linguagem monolíngues, monoculturais e monomodais orientadas por regras. Vivemos numa era de imagens visuais. Nas sociedades pós-mo- 
dernas, a maioria das pessoas passa seu tempo vendo telas de $\mathrm{TV}$, telas de computadores gráficos digitais, ilustrações (muito presentes hoje na mídia impressa e nos livros didáticos) e outros tipos de apresentações visuais.

De acordo com as autoras, na realidade contemporânea, o espaço do "mono" cede espaço para os "multi". Nessa direção, é imperativo propiciar novas incursões sobre os textos multissemióticos para um dimensionamento das questões culturais, estéticas, científicas, técnicas,

Quem conta um conto aumenta um ponto modo a considerar os efeitos dos diferentes recursos na construção das possibilidades de sentidos. Por isso, é importante incentivar produções textuais que explorem as múltiplas linguagens e que impliquem processos de interação com o outro.

Nessa direção, o objetivo geral deste artigo, é estabelecer uma reflexão acerca do trabalho com a produção de textos na perspectiva dos multiletramentos. Mais especificamente, o artigo se propõe a analisar, em um diálogo entre gênero discursivo escrito e outro multissemiótico, como alguns aspectos do multiletramentos estão envolvidos nos processos de produção, circulação e recepção dos textos ${ }^{1}$. Elege-se como propósito discutir sobre a (re)significação da atividade de produção de textos em um contexto multissemiótico. Para isso, toma-se como exemplar uma produção feita por um grupo de alunos de ensino médio - retextualização de um conto com uso de gifs, o que possibilita uma análise das diferentes semioses. Esclarecendo esses termos, pode-se considerar que um GIF animado é um arquivo composto por uma técnica serial de montagem de imagens de baixa resolução, as quais se sucedem automaticamente numa tela de computador ou de dispositivo móvel. Em termos de efeitos estéticos, a animação imprime ao GIF plasticidade, velocidade e repetição, muitas vezes rodando em loop (BERTGES; PEREIRA, 2017). Já a retextualização é a produção de um novo texto a partir de

1 Brait (2002) destaca que as condições de produção e de recepção remetem aos interlocutores, quem produz a mensagem para quem; trata-se da identidade social do produtor e do receptor da mensagem. A circulação refere-se ao veículo ou suporte em que circula o dizer. Tais elementos discursivos são importantes à mensagem como um todo, pois explicam porque aquilo é dito daquela maneira e não de tantos outros modos possíveis. 
um ou mais textos-base, o que implica uma atenção para as estratégias linguísticas, textuais e discursivas identificadas no texto-base para, en-

Helena Maria

Ferreira

Marco Antonio

Villarta-Neder

Geanne dos

Santos Cabral

Coe tão, projetá-las tendo em vista uma nova situação de interação, ou seja, novo enquadre e um novo quadro de referências (MATÊNCIO, 2003). Retextualizar, por meio de ferramentas tecnológicas, demanda habilidades diferenciadas, uma vez que a mobilização de conhecimentos prévios são ressignificados para novos contextos de usos da linguagem.

\section{A TRAJETÓRIA DA PRODUÇÃO DE TEXTO NA ESCOLA}

Considerando que todo processo de interação se efetiva por meio de textos, Geraldi (2003), um dos precursores de uma linha interacionista para o ensino de língua portuguesa, entende que a produção textual como ponto de chegada (ou partida) de todo processo de ensino/aprendizagem da língua, pois, para ele é no texto que a língua se revela em sua totalidade.

Partindo do reconhecimento da relevância dos gêneros discursivos para a instauração de práticas educativas assentadas em princípios que permitam uma articulação com o cotidiano social, direciona-se a discussão para a questão da produção textual. Para Rojo e Cordeiro (2011, p. 8), "a produção textual se concretiza como suporte para desenvolver a habilidade de leitura e redação". No entanto, propiciar momentos de produção de textos não é suficiente para a aquisição e para o aperfeiçoamento de habilidades e competências relacionadas à construção de textos. Na contemporaneidade, a produção de textos não se restringe à modalidade escrita e, muitas vezes, não se configura como uma atividade individualizada. Os textos que circulam socialmente são constituídos por diferentes semioses e são produzidos de modo interativo, que coloca em evidência a própria questão da autoria.

Em conformidade com Knobel e Lankshear (2007), aprender a produzir tipos particulares de textos pressupõe imersão nas práticas sociais, de modo que os participantes possam refletir sobre tais textos, construir atitudes e valores sobre eles e interagir com eles de alguma maneira, uma vez que os textos são elementos integrais de momentos vividos, conversados, encenados, de práticas, crenças carregadas de valor, que circulam em condições específicas, em momentos específicos e em lugares específicos.

É relevante, portanto, pontuar que a assunção de um ponto de vista que situe a produção textual em uma perspectiva social demanda um redimensionamento das práticas educativas, uma vez que existe 
ainda uma forte tendência para adoção de práticas de escolarização de textos desvinculados dos processos de circulação e de recepção, bem como a primazia da linguagem verbal escrita em papel, em detrimento de outras modalidades e de outros suportes. Para uma compreensão acerca do tratamento dado à produção de textos pela escola é importante entender seus percursos históricos.

Segundo Bunzen Jr. (2007), no final do século XVIII até meados do século XX, o ensino da língua se limitava à cobrança das regras (por meio da memorização) e da leitura, deixando de lado a importância de escrever. Nesse contexto, o texto produzido em sala de aula era designado composição e era construído com o objetivo de embasar a gramática, explorando um vocabulário que revelasse competência intelectual. As “composições" ensinadas na escola pertenciam às disciplinas de retórica,

Quem conta um conto aumenta um ponto poética e literatura nacional. Era por meio da linguagem que se organizava a expressão do pensamento. $O$ interesse principal dessas composições era analisar o processo de raciocínio utilizado em sua construção e não a finalidade de se pensar o texto. Logo, era um texto construído para apresentar domínio da língua culta e tomava como base a imitação de trechos de autores consagrados, apresentados como modelos.

Para Guedes (2012, p. 88), essa fase pode ser denominada de "era da composição".

\footnotetext{
A palavra composição, usada para designar textos escritos na escola, [...] vincula-se à mesma teoria que dá embasamento à gramática tradicional e vê a linguagem como instrumento de organização e de expressão do pensamento dentro dos princípios da chamada lógica formal. Interessa mais a correção do processo de raciocinar do que a finalidade com que o raciocínio é ensinado.
}

Nessa perspectiva, Rojo (2009) pontua que essa postura sustenta a crença de que escrever seria um dom, que estaria outorgado apenas a determinadas pessoas.

Nas décadas de 50 a 70, surgiram os estudos sobre a escrita numa perspectiva intitulada pelos teóricos de "era da redação" (GUEDES, 2012). Bunzen Jr. (2007) considera que a criatividade passa a ser incentivada, porém o processo de estímulo de escrita ainda parte de leituras, a fim de mostrar o exemplo a ser seguido. Os objetivos, os procedimentos 


\begin{abstract}
Helena Maria
Ferreira

Marco Antonio

Villarta-Neder

Geanne dos

Santos Cabral

Coe metodológicas que tornassem a redação prática e útil, isto é, o aluno passou a ser reconhecido como aquele que irá emitir e receber mensagens, será ensinado a utilizar e compreender códigos diversos - verbais e não-verbais. Assim, as redações produzidas pelos alunos passam a ser classificadas como "atos de comunicação e expressão".

Complementando o exposto, Pinton e Gonçalves (2012) consideram que essa fase ainda trazia resquícios da fase anterior em que a escrita era vista como resultado da apropriação das normas gramaticais, com a diferença de ser vista como resultado de um momento criativo, baseado nas tipologias textuais: narração, descrição e dissertação, com ênfase nas estruturas desses tipos. Tais tipos eram apresentados linearmente, assumindo a perspectiva de um ensino prescritivo e normativo.

A partir de 1980/1990 e, de modo mais incisivo, com a publicação dos Parâmetros Curriculares Nacionais, diante da constatação de que o ensino de regras textuais e gramaticais não fornecia ferramentas para uma prática de produção de textos satisfatória, o texto passa a ser o centro do ensino. Assim, essa prática linguística passa a ser denominada de produção de texto, em que é comparada às ações de cultivar a terra, consertar sapatos, dar aulas. Trata-se de uma atividade, não de organizar, mas de produzir, transformar, mudar, mediante a ação humana. (GUEDES, 2012). Assim, a concepção de língua que fundamenta essa perspectiva é vista como uma forma de ação, processo de estabelecer vínculos, de criar compromissos entre interlocutores. Nessa perspectiva, é relevante que os alunos entendam que a escolha do repertório de possibilidades textuais de ser feita de acordo com as demandas das interações sociais. Assim, segundo Baltar (2003, p. 3),
\end{abstract}

didáticos e a formulação de métodos para o ensino de língua materna sofrem alterações significativas. Passou-se, então, a buscar estratégias

diferentemente de um aluno que escreve uma mera redação, um usuário competente discursivamente é aquele que pensa a produção de textos, situando-os dentro de um gênero com sua estrutura estável, que pertence a um ambiente discursivo, como produção escrita dialógica, que busque atingir sócio-comunicativos específicos. É aquele sujeito-produtor que pretende interagir com outros sujeitos dentro de uma instituição dada, de acordo com as situações de uso real da língua, que compreenda o mundo discursivo e as possibilidades de expressão de acordo 


\begin{abstract}
com a variedade de gêneros textuais que esse mundo discursivo possibilita, levando-se em consideração não só o produto da interação - os textos e seus mecanismos de textualização mas todo o processo de enunciação que sustenta as atividades de linguagem dentro das diversas instituições sociais. (BALTAR, 2003, p.3)
\end{abstract}

No entanto, essa concepção que natureza social e interativa da Quem conta linguagem não tem produzido efeitos substanciais nas salas de aula, um conto uma vez que as atividades de produção de textos ainda apresentam aumenta um resquícios de abordagens tradicionais. Nesse contexto, embora haja ponto um reconhecimento dessas questões por parte dos professores, ainda existe uma tendência em se ignorar a dinamicidade da linguagem. Para Castaldo (2009, p. 40), essa tendência tem propiciado a propagação de uma crença por parte do aluno de que a "interação verbal deve ser rigidamente concretizada em formatos definidos por imperiosas leis de formação dos diversos gêneros do discurso." Nesse sentido, observa-se que são criados moldes que devem formatar o que se quer expressar. Para a autora, "emerge o desejo de se demonstrar, de se demarcar o saber-fazer. Apaga-se o "eu" que deseja exteriorizar-se com identidade e atingir o "outro"” (p. 40). Assim, recorrentemente, é comum deparar-se com uma escrita sem voz própria, pouco fluente, desarticulada, truncada, em que desaparece a criação e se amarra a palavra.

Pécora (1986) comenta sobre as chamadas "estratégias de preenchimento", isto é, recursos de preenchimento de uma estrutura vazia em uma produção textual. Esse procedimento evidencia uma tendência para práticas de ensino que evidenciem a reprodução de modelos, isto é, o exercício de cristalização de formas, o que não caracteriza uma escrita efetivamente autoral, como descrito por Orlandi (1988), mas um simples sujeito que apenas repete dizeres. A interação é praticamente desconsiderada. Essa tendência desencadeia uma problematização: trabalhar com textos não significa, necessariamente, trabalhar com gêneros discursivos.

Segundo Geraldi (2003), uma produção de textos que implica a dimensão social da linguagem deve contemplar: 1) Ter o que dizer (a) - Não é trazer para a escola o que ela (a escola) diz, mas, sim, o que ela não sabe: experiências individuais e seus significados no contato com outros; 2) Razões para dizer (b) - É necessária uma motivação interna 
para a realização do trabalho. Ter um motivo para construí-lo; 3) Definição de interlocutores (c) - Ao considerar os diversos níveis de uso da Helena Maria linguagem, incentivar produções com destino a interlocutores reais ou Ferreira possíveis; 4) A escolha de estratégias (e) - São decididas em função tanto do que se tem a dizer quanto das razões para dizer a quem se diz.

Marco Antonio

Villarta-Neder

Geanne dos

Santos Cabral

Coe

Corroborando a posição de Geraldi (2003), Antunes (2003) afirma que a escrita é uma atividade interativa, isto é, conta com a participação de interlocutores. Segundo a autora, "o professor não pode, sob nenhum pretexto, insistir na prática de uma escrita escolar sem leitor, sem destinatário; sem referência, portanto, para se decidir sobre o que vai ser escrito" (2003, p. 47). Além disso, a autora ainda ressalta que a produção de textos na escola não pode estar desvinculada de sua função social, "pela escrita alguém informa, avisa, adverte, anuncia, descreve, explica, comenta, opina, argumenta, instrui, resume, documenta, faz literatura, organiza, registra e divulga o conhecimento produzido pelo grupo" (p. 48).

Desse modo, reitera-se que o panorama histórico que situa o lugar da atividade de escrita na tradição escolar tem sofrido avanços substanciais no que diz às concepções, no entanto, é possível conjecturar uma dissociação entre os redimensionamentos teóricos e os processos de ensino-aprendizagem. Nesse contexto, considera-se que a produção de textos em uma perspectiva dos multiletramentos parece ser um prognóstico de uma nova fase, em que diferentes semioses participam da textualidade das produções sígnicas, demandando uma reconfiguração dos cursos de formação de professores e das práticas didático-pedagógicas.

Feito esse retrospecto histórico, cabe estabelecer, para o escopo desse artigo, que essa concepção mais ampla, efetivamente de gêneros discursivos, implica considerá-los enquanto enunciados, dentro de uma perspectiva bakhtiniana. Bakhtin diz que

Os limites de cada enunciado concreto como unidade da comunicação discursiva são definidos pela alternância dos sujeitos do discurso, ou seja, pela alternância dos falantes. Todo enunciado - da réplica sucinta (monovocal) do diálogo cotidiano ao grande romance ou tratado científico - tem, por assim dizer, um princípio absoluto e um fim absoluto: antes do seu início, os enunciados dos outros; depois do seu término, os enunciados 
responsivos de outros (ou ao menos uma compreensão ativamente responsiva silenciosa do outro ou, por último, uma ação responsiva baseada nessa compreensão). (BAKHTIN, 2016, p 29)

É necessário colocar esse trecho em diálogo com outro, no qual Bakhtin conceitua os gêneros discursivos:

\footnotetext{
O emprego da língua efetua-se na forma de enunciados (orais e escritos) concretos e únicos, proferidos pelos integrantes desse ou daquele campo de atividade humana. Esses enunciados refletem as condições específicas e as finalidades de cada referido campo não só por seu conteúdo (temático) e pelo estilo da linguagem, ou seja, pela seleção dos recursos lexicais, fraseológicos e gramaticais da língua, mas acima de tudo, por sua construção composicional. Todos esses três elementos [...] estão ligados no conjunto do enunciado e são igualmente determinados pela especificidade de um campo da comunicação. Evidentemente, cada enunciado particular é individual, mas cada campo de utilização da língua elabora seus tipos relativamente estáveis de enunciados, os quais denominamos gêneros do discurso. (BAKHTIN, 2016, pp. 11-12)
} Quem conta um conto aumenta um ponto

Portanto, é importante estabelecerem-se algumas relações. Em primeiro lugar, assumir que gêneros discursivos são enunciados. Como tais, definem-se por esse diálogo entre com os precedentes e os subsequentes, não meramente como uma relação entre textos, mas como ações de sujeitos do discurso que se alternam nas posições em que se constituem, sempre ativamente - ainda quando compreendem o enunciado alheio -, inevitavelmente mergulhados na unidade do acontecimento, em suas dimensões semiológicas, sociais, históricas, culturais e antropológicas.

Ainda, importa considerar que essa construção composicional dos enunciados, sejam eles na esfera singular em que cada sujeito se constitui na relação com outro (sujeito), seja nas esferas de atividade que congregam (e são constituídas por) esses enunciados, pode ser multissemiótica. Dentro do próprio enunciado, podem haver diálogos entre signos de semioses diversas. 


\section{OS MULTILETRAMENTOS E A PRODUÇÃO DE TEXTO NA ESCOLA CONTEMPORÂNEA}

Helena Maria Devido aos constantes debates sobre questões de como trabalhar a Ferreira língua portuguesa no século XXI, mudanças estão em andamento e entende-se que os cidadãos estão, recorrentemente, inseridos em

Marco Antonio

Villarta-Neder

Geanne dos

Santos Cabral

Coe um contexto de múltiplas linguagens, o que, por sua vez, demanda novos (multi)letramentos. Diante da diversidade de recursos digitais, as atividades de leitura e de produção textuais estão se tornando mais complexas, nossos suportes textuais estão mais evoluídos ou diversificados, o que exige, consequentemente, uma reorganização de hábitos mentais e práticas de leitura e escrita (DIONÍSIO; VASCONCELOS, 2013).

Essa reorganização está intrinsecamente relacionada às habilidades dos sujeitos em receber e produzir textos multissemióticos, o que demanda a percepção dos múltiplos recursos constitutivos dos textos e de suas potencialidades para o processo de construção de sentidos. Nessa direção, Ferreira e Villarta-Neder (2017, p. 69) pontuam que

\footnotetext{
com a disseminação das tecnologias, os gêneros discursivos foram reconfigurados, assumindo novos formatos estruturais $\mathrm{e}$ novas formas de organização. Desse modo, os textos conjugam modalidades (fala, escrita, imagens) e semioses (cores, sons, diagramação, planos, movimentos etc.), demandando do leitor novas habilidades para a depreensão dos elementos e das combinações sígnicas que participam do processo de produção dos sentidos.
}

Nessa perspectiva, vale pontuar que produzir textos multissemióticos exige habilidades relacionadas aos multiletramentos, pois não apenas o domínio operacional de ferramentas tecnológicas é demandado, mas também a seleção de semioses, as combinações sígnicas e suas formas de organização a serem utilizadas para direcionar sentidos e para evocar interpretações. Nesse contexto, Joly (2012, p. 29) assevera que "de fato, um signo só é "signo" se "exprimir ideias" e se provocar na mente daquele ou daqueles que o percebem como uma atitude interpretativa." A escolhas dos signos/semioses representa uma maneira de os usuários da língua realizarem seu projeto de dizer e um meio estratégico de orientar o sentido pretendido. 
Desse modo, de acordo com Street (2014, s/p.),

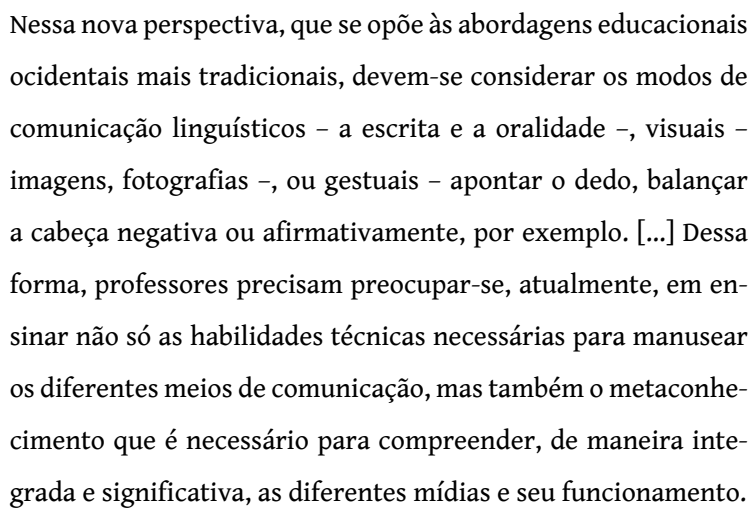

Quem conta

um conto

aumenta um

ponto

Assim, a realidade multimodal pressupõe a diversidade de recursos linguístico-semiótico-discursivos, o que exige a reconfiguração das metodologias de ensino. Essa realidade mobiliza uma atuação docente voltada para o encaminhamento de atividades didático-pedagógicas que vislumbrem novas possibilidades de interação, mediadas pelas tecnologias.

A proposta de ensino sob a perspectiva dos multiletramentos abarca a realidade do aluno (sua cultura, sua linguagem, suas experiências) para o interior da sala de aula, aproximando histórias e promovendo o diálogo entre culturas e vivências presentes no ambiente, viabilizando a produção de textos compostos de várias linguagens (ou modos ou semioses) e que exigem capacidades e práticas de compreensão e produção de cada uma delas (multiletramentos) para fazer significar" (ROJO, 2016, p. 19).

Ao discutir sobre o ensino da produção de textos na contemporaneidade, é relevante considerar que, se antes, o aluno produzia os textos para avaliação do professor, com as possibilidades de conexão à rede para distribuição dos textos, foram ampliadas as atividades de produção colaborativa (produção conjunta), as participações interativas (comentários acerca do conteúdo produzido), a conjugação de diversas mídias e linguagens (verbais, visuais e sonoras), o que culmina em uma reconfiguração do direito autoral, já que as produções são constantemente retextualizadas e ressignificadas.

Nesse contexto, a organização de um texto se efetiva por meio de recursos linguísticos apenas, por meio da escrita, ao contrário, ele pode se materializar por meio da linguagem escrita, oral e/ ou imagética, bem como da articulação/ integração dessas modalidades. Recursos 


\begin{abstract}
Helena Maria Ferreira falas, combinação de sons com textos falados etc.) são indiciadores de sentidos. Assim, é preciso repensar o processo de ensino-aprendizagem das práticas de produção de textos em âmbito escolar.
\end{abstract}

visuais (ícones, imagens, cores, tipos de letras, combinação de letras, de palavras, de frases etc.) e recursos sonoros (sons, ruídos, gravação de

Marco Antonio Villarta-Neder

Geanne dos Santos Cabral

\title{
4. O TRABALHO COM AS SEMIOSES NA PRODUÇÃO TEXTUAL
}

Durante décadas, os professores de português experimentaram estar diante de sua turma com uma proposta de produção de texto, orientar o tema e aguardar que o aluno devolvesse a folha repleta de ideias e imaginação, para mais uma avaliação. Depois, apenas ele (o professor) diante dos textos produzidos, era o momento de verificar se o objetivo pretendido ao cobrar a produção havia sido alcançado. Mas qual era o objetivo?

Ao relembrar a trajetória do ensino de produção de texto ao longo da história como relatado anteriormente, é possível perceber uma preocupação intensa, durante muito tempo, com uma escrita de qualidade, domínio das regras, uso formal da língua e a busca por alcançar um padrão culto a partir do exercício de escrita usando outros textos como modelo.

Em seguida, o foco tornou-se trabalhar os gêneros textuais/discursivos ${ }^{2}$, ainda incentivando o zelo pela língua, mas partindo de leituras e interpretações até chegar às produções escritas pelos alunos. No entanto, ainda hoje, essas produções são entregues pelos estudantes, avaliadas pelo professor e, geralmente, devolvidas apenas com uma nota, sem que outros tenham a oportunidade de ler o que fora escrito. De modo geral, há pouco incentivo em apresentar aos colegas de classe ou aos pais o conteúdo desenvolvido pelo autor daquele texto.

Nesse contexto, é imprescindível que experiências que contemplem o trabalho com as semioses em ambiente escolar sejam socializadas para que a produção de textos seja ressignificada pelos professores e pelos alunos.

\footnotetext{
2 Não se considera, no âmbito deste artigo, gêneros discursivos e gêneros textuais como conceitos iguais. Na maioria das vezes, o conceito de gêneros textuais ressignifica o contexto epistemológico e axiológico advindo do referencial bakhtiniano. $O$ estudo dos gêneros discursivos contempla primeiramente as instâncias sociais, ou seja, "os aspectos sócio-históricos da situação enunciativa, privilegiando, sobretudo, a vontade enunciativa do locutor - isto é, sua finalidade, mas também e principalmente sua apreciação valorativa sobre seu(s) interlocutor(es) e tema(s) discursivos - e, a partir desta análise, as marcas linguísticas (formas de texto enunciado e da língua - composição e estilo) que refletem no enunciado/texto, esses aspectos da situação" (ROJO, 2005, p. 196).
} 
Com vistas a refletir sobre o trabalho com as diferentes semioses, será relatada aqui uma experiência de pesquisa sobre produção de textos realizada por uma das autoras deste artigo, que envolveu alunos de ensino médio de uma escola rural ${ }^{3}$. Essa pesquisa conta com uma proposta de produção de diferentes gêneros discursivos em contextos multissemióticos.

A atividade aqui descrita consistiu de uma leitura de vários contos e de um estudo sobre os modos de organização desse gênero discursivo. A partir dessa leitura, foi selecionado o conto: As meninas (Ana Elisa Ribeiro, do livro Beijo, boa sorte!,), para que os alunos fizessem uma retextualização, utilizando diferentes semioses para além da linguagem verbal. Segue o conto:

Quem conta um conto aumenta um ponto

Antes não usava moça ir a bar, tocar violão e dirigir. Antes também não usava moça de calça comprida. Não usava menina na janela depois de certa hora. Não usava batom vermelho nem muito menos escarlate na roupa de baixo. Não usava moça namorar até tarde. Nem ficar sem sutiã. Nem falar alto e abrir a perna. Não usava moça andar com rapazes. Não usava moça sorrir para estranhos. Nem ir ao médico de mulheres. Nem ficar sem marido depois dos 22 anos. Nem fazer sexo antes de casar. Não usava moça não usar anágua. Não usava moça que pinta a unha de carmim. Não usava, faz pouco tempo, moça que trabalha fora. Não usava moça que lê e escreve. Moça não usava. Moça não servia para quase nada. Moça não servia para quase nada. (RIBEIRO, 2015).

A leitura do conto propiciou uma discussão sobre o papel da mulher na sociedade. Além dos textos que abordavam a temática propostos pela professora, os alunos pesquisaram músicas, documentários, peças publicitárias etc. Após a discussão, os alunos foram solicitados a retextualizarem o conto, utilizando recursos semióticos para veiculação em formato digital.

Entre as várias retextualizações produzidas pelos alunos, foi selecionada para discussão apenas uma produção, que utilizou o formato gif (Graphics Interchange Format) para a organização do texto.

3 Pesquisa aprovada pelo COEP sob o n. 92656618.6.0000.5148. 
De acordo com Bertges e Pereira (2017, p. 492),

Helena Maria
Ferreira
Marco Antonio
Villarta-Neder

Geanne dos

Santos Cabral

Coe

O suporte, como integrante e mesmo determinante de novas experiências estéticas, fomenta distintas formas de interação e leituras de textualidades poéticas. No contexto dos novos suportes advindos da revolução digital, o formato GIF, popular em ambientes virtuais, tem sido usado em processos de reelaboração de poemas originalmente publicados em meio impresso.

No caso em pauta, o formato gif foi utilizado para a retextualização do conto de Ribeiro, por meio do uso de várias imagens, as quais são analisadas a seguir, a partir de capturas de telas do vídeo produzido. Para melhor compreensão da análise aqui realizada, recomenda-se ao leitor do presente artigo que acesse o link https://youtu.be/-UJV2aRmqj4. A opção pelo uso do YouTube possibilitou um redimensionamento dos processos de produção, veiculação e recepção do produzido, que se desloca do suporte impresso em papel para novas interações mediadas por suportes tecnológicos (celulares, computadores, tabletes etc).

A produção, em formato de um vídeo, apresenta a parte verbal, produzida por Ribeiro (2015), sem alterações. Para cada parte, foi selecionado, pelo grupo de alunos, um gif que representasse o conteúdo apresentado. A retextualização demandou uma interpretação e uma análise do GIF mais adequado à situação retratada. O conto, por si só, já mobilizou a atenção dos alunos, mas ao ser "multissemiotizado", as discussões foram mais intensas.

Merecem destaque as estratégias encontradas pelos alunos na seleção dos gifs para mobilizar a atenção dos leitores-espectadores. A análise aqui empreendida busca verificar os recursos semióticos utilizados pelos alunos para tornar a retextualização mais interativa. Entre os recursos utilizados, sobrelevam-se as estratégias de humor.

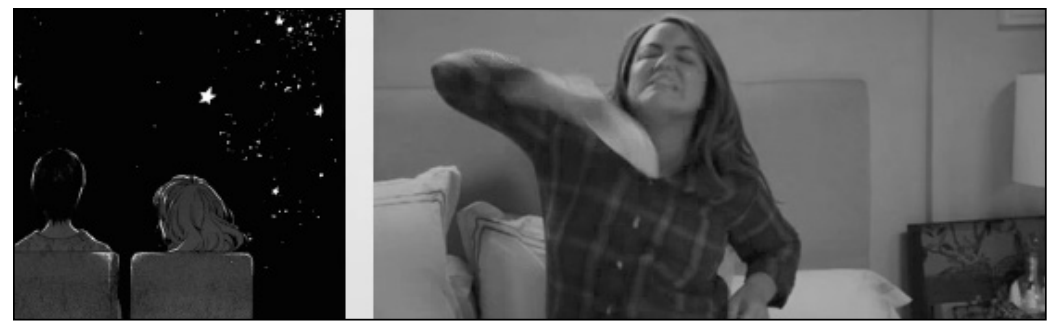

Figura 1: Moça ficar sem sutiã 


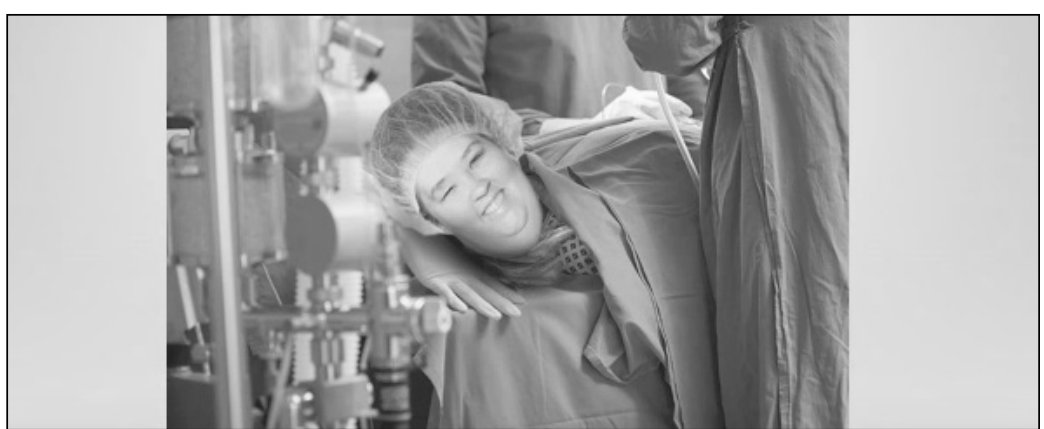

Figura 2: Moça não ir ao médico de mulheres

O humor é provocado na figura 1 pelo movimento abrupto da moça para se livrar da peça íntima e na figura 2 pela expressão facial da moça. Esses recursos além de servir como um apelo para prender a atenção do leitor, configuram como uma estratégia que imprime um tom irônico, o que coaduna com a proposta do conto original. Várias pesquisas, segundo Ottoni (2007), enfatizam os benefícios do humor no contexto escolar: reduz a ansiedade, cria uma atmosfera mais positiva e aberta, torna a aula mais interessante, mantém a atenção dos alunos, promove a interação e discussão em sala de aula, ajuda na assimilação de conteúdos e informações. o humor promove o pensamento divergente. Enquanto na educação em geral ensina-se o pensamento convergente, em que o professor direciona para uma resposta única, o humor abre possibilidades de respostas, de um outro sentido.

Outra questão digna de nota são os movimentos, que não são tomados apenas pela alternância de imagens, mas orientam determinados sentidos, conforme figuras 3 e 4 :

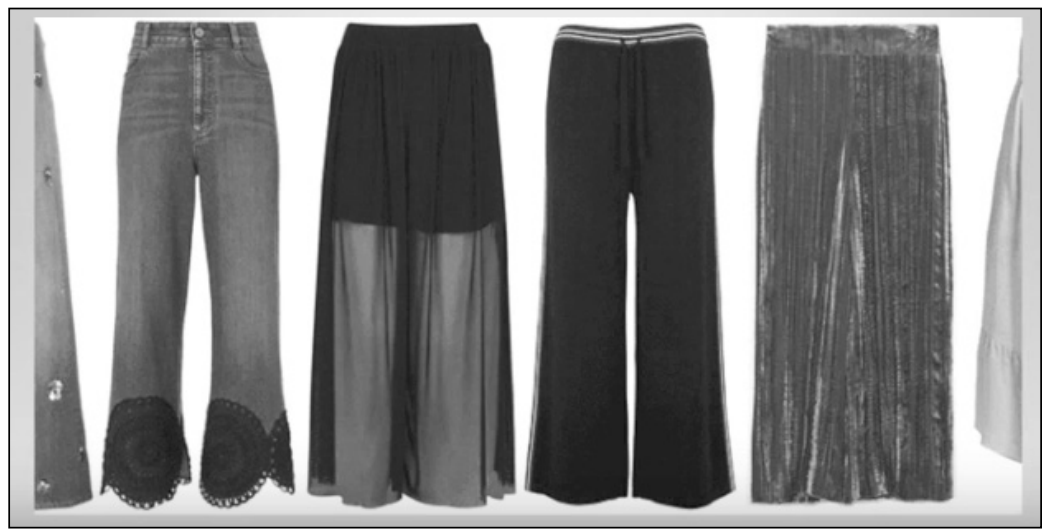

Figura 3: Moça não usava calça comprida
Quem conta um conto aumenta um ponto 


\section{Helena Maria \\ Ferreira \\ Marco Antonio \\ Villarta-Neder}

Geanne dos

Santos Cabral

Coe

144

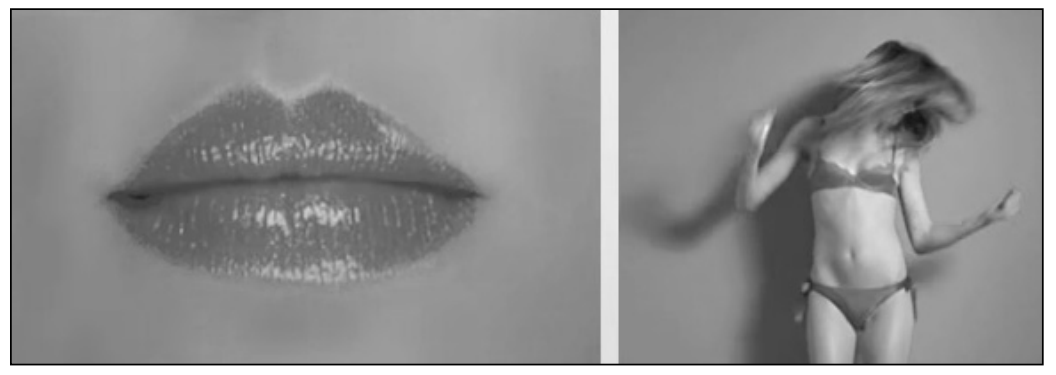

Figura 4: Moça não usava escarlate na roupa de baixo

$\mathrm{Na}$ figura 3, a escolha parece desvelar a diversidade de opções de calças que as mulheres encontram no mercado. Nesse contexto, o gif selecionado indicia para a liberdade feminina para adotarem um estilo que combina com as suas preferências pessoais. Na figura 4, o movimento parece insinuar uma sensação de irreverência, de liberdade. Na imagem da esquerda, a boca simula um envio de um beijo e na imagem da esquerda o movimento indicia uma dança que sugere libertação das amarras sociais. A seleção de imagens em movimento, de gifs, no caso deste estudo, assume importância substantiva na formação crítica dos alunos, pois pressupõe uma abordagem crítica que segundo Dudeney, Hockly e Pegrum (2016, p. 17) demanda "habilidades individuais e sociais necessárias para interpretar, administrar, compartilhar e criar sentido eficazmente no âmbito crescente dos canais de comunicação digital". Essas ações impulsionam os alunos a redesenhar textos e sentidos. $O$ acesso a situações de criação de conteúdo, crítica e de circulação de sentido possibilita aos alunos assumirem o papel de protagonistas e não o de mero receptores de conteúdo e pode estimulá-los à participação social, permitindo a eles propor seus próprios pontos de vista.

Além das questões destacadas, ressalta-se também a questão da imagem hiperbólica, que desloca o conceito de hipérbole como palavra que exagera para um dispositivo discursivo que, com vários elementos discursivos, constrói o exagero." (RESENDE, CANO, 2017, p. 114). Dessa forma, o exagero da hipérbole, a fim de realçar uma ideia, pode exagerar causando assim um efeito humorístico, buscando evidenciar uma crítica social. Nesse caso, tem-se as figuras 5 e 6: 


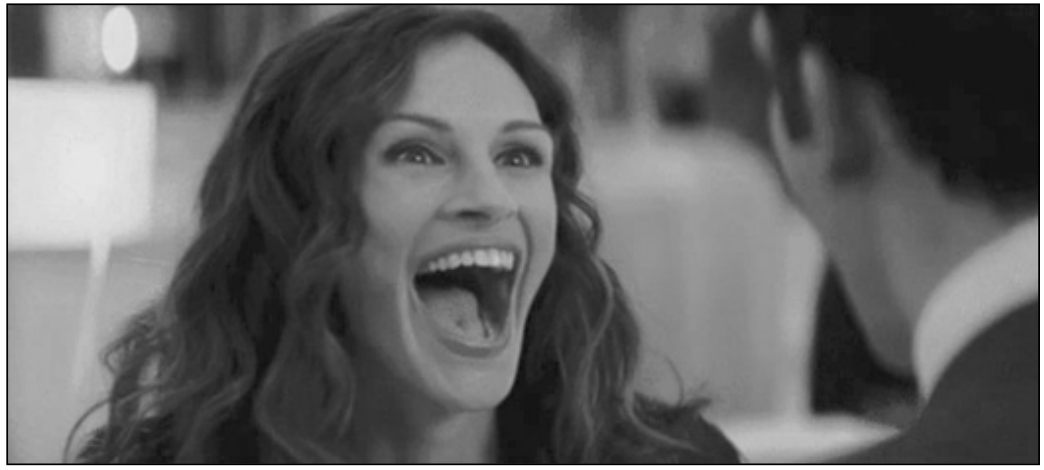

Figura 5: Moça não sorri para estranhos

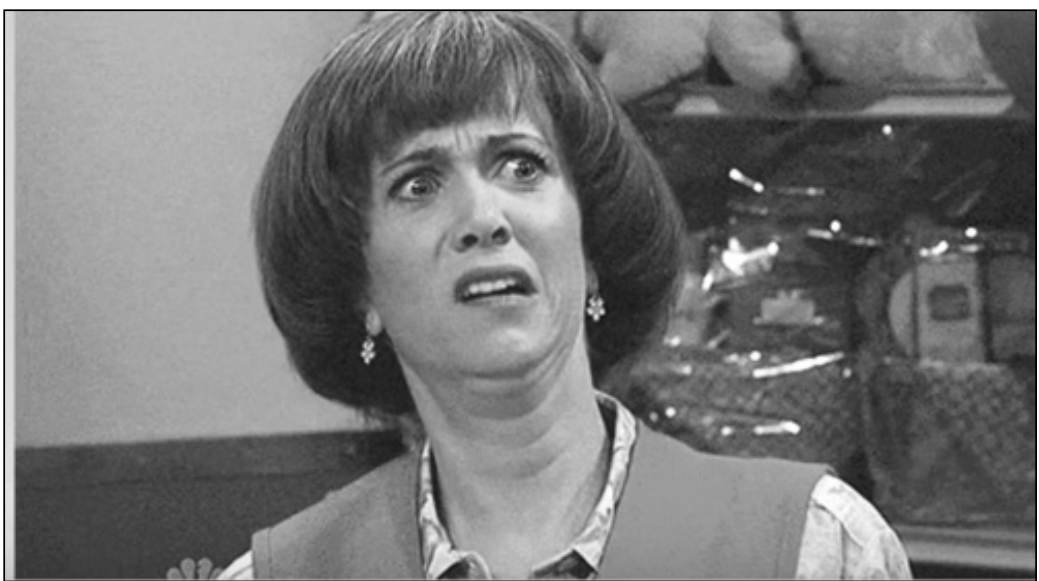

Figura 6: Moça não servia para quase nada

$\mathrm{Na}$ figura 5, evidencia-se a imagem de uma atriz com a boca bastante aberta, indo ao encontro do que afirma o enunciado "Não usava moça sorrir para estranhos." Essa escolha demonstra a percepção por parte dos estudantes da ironia presente no texto. Na figura 6, o exagero se evidencia na expressão facial da mulher que apresenta uma ideia de que a afirmação "Moça não servia para quase nada" é absurda, da qual ela discorda.

Nesse sentido, observa-se que os alunos, ao produzirem o vídeo por meio de gifs, não somente tiveram que apresentar um domínio técnico das ferramentas de criação de vídeo, de inserção de imagens e de áudio, eles tiveram que mobilizar conhecimentos prévios sobre o conteúdo abordado, o que pode contribuir para um redimensionamento da atividade de produção de textos na escola.
Quem conta

um conto

aumenta um

ponto 
Por fim, vale destacar a criatividade e atenção aos detalhes. $\mathrm{Na}$ figura 7, observa-se que a janela está vazia, o que corresponde ao ex-

Helena Maria

Ferreira

\section{Marco Antonio}

Villarta-Neder

Geanne dos

Santos Cabral

Coe certo "Não usava menina na janela depois de certa hora". Na figura 8 , a representação do fim do conto, que normalmente aparece a palavra "fim". Aqui, aparece em uma versão de gif, modernizada por meio de "Bye" e "acabou".

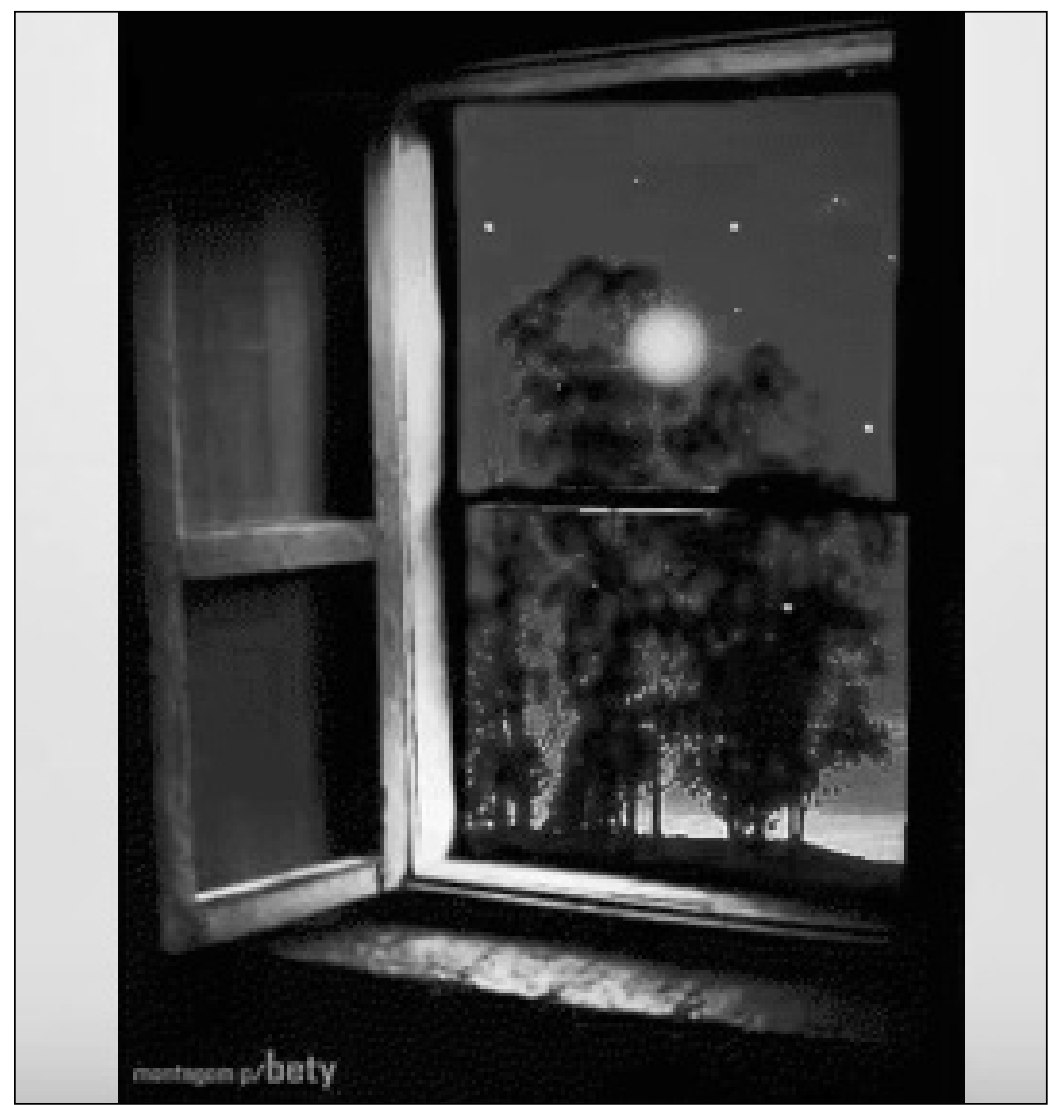

Figura 7: Moça não fica na janela à noite

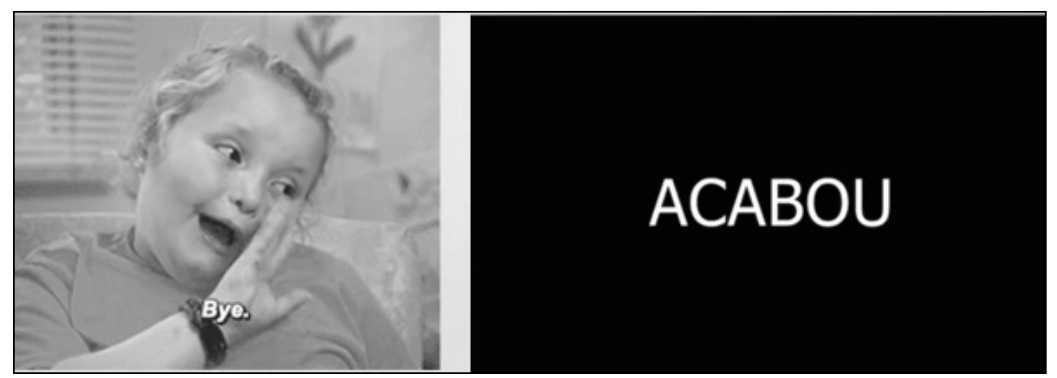

Figura 8: Indicação de fim 
A experiência de produção de textos, ora analisada, evidencia a posição de Custódio (2016, p. 199), que assegura

\begin{abstract}
Formar cidadãos autônomos em uma sociedade cada vez mais tecnologicamente complexa, sem escamotear a cultura local e global com as quais os sujeitos se relacionam, é, sem dúvida, papel da escola. E para cumprir esse objetivo, o ensino deve mobilizar múltiplos letramentos, ou seja, abordar diferentes mídias, diferentes semioses, em contextos culturais diversos.
\end{abstract}

É por meio da escola que questões relacionadas ao cotidiano dos alunos, tal como a visão crítica acerca do lugar histórico e social da mulher, podem ser problematizadas e trazidas para uma reflexão, com vistas à formação do cidadão crítico e reflexivo. Como comentam Vieira et al. (2016, p. 181), “é indispensável um ensino de língua portuguesa que desenvolva um processo de leitura/escrita em que o aprendiz se coloque como leitor crítico e autônomo."

Refletindo sobre o processo de produção de textos analisado, pode-se fazer menção à posição de Teixeira e Moura (2016, p. 55) que salientam que "a necessidade de (re)pensar o conceito de letramento a partir da mudança da cultura do papel para a cultura da tela e da coexistência entre as tecnologias tipográficas e digitais de leitura e escrita na atualidade". Nesse contexto, o trabalho com as multissemioses dá novos sentidos à produção, sem demérito para o valor dos textos verbais escritos em papel.

Outro ponto a ser ressaltado é que todo texto se organiza dentro de determinado gênero em função das intenções comunicativas, como parte das condições de produção dos discursos, os quais geram usos sociais que os determinam. Desse modo, ao incentivar a produção de texto em uma perspectiva dos multiletramentos, solicita-se também o conhecimento de gêneros discursivos que circulam na sociedade da informação, abarcando em suas múltiplas semioses.

De acordo com Rojo (2016), é relevante que considerar, na pedagogia dos multiletramentos, os quadrantes propostos Grupo de Nova Londres explicitam diferentes tipos de letramentos.
Quem conta um conto aumenta um ponto 


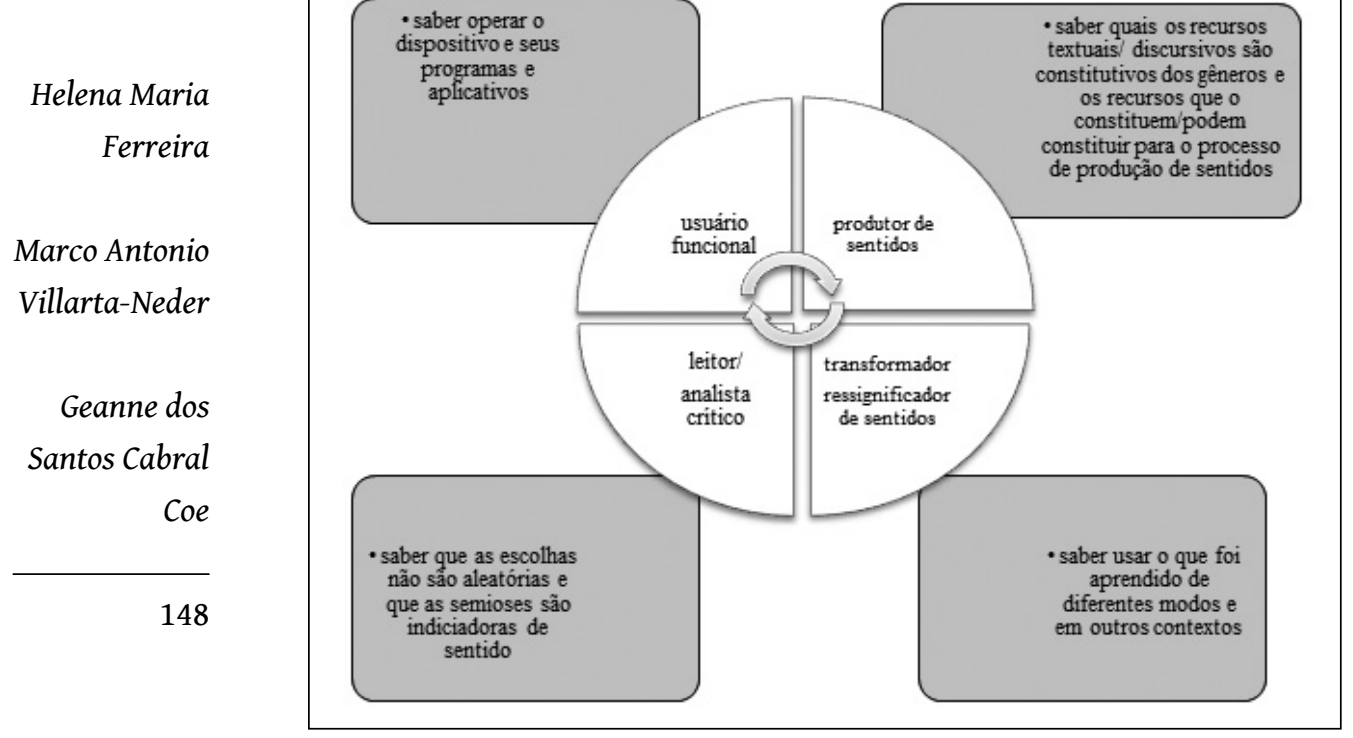

Figura 9: Quadrantes proposto pelo Grupo Nova Londres (adaptado de ROJO, 2016)

O primeiro quadrante representa uma dimensão que se relaciona ao letramento digital básico, que diz respeito às habilidades dos sujeitos de operarem ferramentas e artefatos tecnológicos para atender às demandas do cotidiano social. O segundo quadrante representa o letramento multissemiótico, que implica habilidades relacionadas ao saber usar as múltiplas semioses para o processo de produção de sentidos, em conformidade com as situações discursivas. $O$ terceiro quadrante relaciona-se ao letramento crítico que se refere à habilidade de análise reflexiva acerca dos diferentes usos da linguagem em seus diferentes contextos e da adequação aos projetos de dizer. Por fim, o quarto e último quadrante, que abarca os diferentes tipos de letramentos aludidos anteriormente e que se relaciona às habilidades de usos sociais da linguagem, de modo proficiente e crítico no processo de produção de sentidos imanentes das interações sociais.

Nessa direção, Dias (2016, p. 95) complementa que

Na contemporaneidade, as novas tecnologias de informação e de comunicação - TICS - têm exigido práticas letradas que requerem um deslocamento das práticas canônicas realizadas pelos protagonistas do cenário das escolas de ensino 
médio, os professores e os alunos. As TICS trouxeram para o contexto escolar textos multimodais e multissemióticos que combinam imagens estáticas (e em movimento), com áudios, cores e links.

Com as novas tecnologias, não há mais uma limitação do espaço onde o texto se desenvolve e não há mais regras intransponíveis. Os recursos digitais possibilitam a combinação entre escrita e imagens; cores e áudios. E como afirmam Vieira et al. (2016, p. 185), “as produções multimodais ou multissemióticas vão além da mera soma das várias modalidades em determinado meio de circulação e nos levam a refletir sobre como os significados são ampliados, transformados e multiplicados". Enfim, elas implicam um sujeito ativo.

Quem conta um conto aumenta um ponto

Bakhtin, no contexto russo dos anos 1940, faz uma consideração que dialoga com essa preocupação. $O$ autor reitera que "o destino posterior das capacidades criativas de um jovem depende muito da linguagem com a qual ele se forma no ensino médio. 0 professor tem essa responsabilidade." (BAKHTIN, 2013, p. 43). Considerar hoje, no século XXI, essa linguagem do/para o aluno é levar em conta o ambiente multissemiótico em que a produção, circulação e recepção dos enunciados se constrói.

$\mathrm{Na}$ retextualização do conto, os alunos foram capazes de dialogar com práticas socioculturais de sua própria realidade. 0 efeito de humor nasceu do diálogo com algumas dessas práticas, a maioria das quais, vivenciadas no cotidiano desses alunos. No texto citado supra, Bakhtin fala também de como o posicionamento do aluno como sujeito implica manusear a forma (composicional) da língua. Não é diferente com relação a outras semioses. $O$ que os alunos criaram, na retextualização, foi mais que uma transposição de signos. Foi uma leitura de como brincar com os posicionamentos do miniconto, feitos por outro sujeito, construindo um posicionamento deles, com outro projeto de dizer.

Essa atitude pode ser entendida à luz do que discutimos sobre Geraldi (2003). Os alunos tiveram o que dizer, razões para dizer, estratégias para dizer porque, na relação interlocutiva com interlocutores que perceberam existir para seus enunciados, assumiram-se como locutores. Tratar de multiletramentos, dessa perspectiva, é entender esses sujeitos nesses posicionamentos, na possibilidade se sentirem sujeitos, dialogando com outros sujeitos, e de como os signos de diferentes linguagens participam desse diálogo. 


\section{CONSIDERAÇÕES FINAIS}

Foi objetivo geral deste artigo estabelecer uma reflexão sobre o tra-

Helena Maria

Ferreira

Marco Antonio

Villarta-Neder

Geanne dos

Santos Cabral

Coe

150

balho com a produção de textos na perspectiva dos multiletramentos. Como objetivos específicos, buscou-se analisar em um diálogo entre gênero discursivo escrito e outro multissemiótico, como alguns aspectos do multiletramentos estão envolvidos na compreensão desse gênero discursivo. Discutiu-se, para isso, uma produção feita por alunos de ensino médio - retextualização de um conto com uso de gifs.

As tecnologias têm atuado de modo significativo no espaço educacional, viabilizando espaços para que aulas mais dinâmicas e interativas façam parte da realidade dos alunos. Por essa razão, é necessário salientar que a questão dos multiletramentos é uma demanda da sociedade contemporânea em que textos multissemióticos têm trazido novas formas de interagir socialmente. Nesse contexto, a recepção e a produção de textos se reconfiguram, em função dos novos processos de circulação, em que compartilhamentos e as reedições alteram contextos e as questões autorais. A produção de textos, em uma perspectiva dialógica, parte do pressuposto de que a produção de sentido se realiza em um dado contexto em que sujeito e interlocutor estão irrevogavelmente atrelados. O sujeito não se expressa apenas, ele age, atua com seu interlocutor, esperando deste uma resposta. Ao produzir textos de circulação mais ampla (para além do texto escrito para correção do professor), os alunos puderam refletir sobre o papel do interlocutor no processo de produção de sentidos.

Com a emergência das tecnologias da comunicação e da informação, novas demandas de produção de textos são impostas, já que diferentes realidades coexistem: produção colaborativa, produção comentada, redimensionamentos dos processos autorais, diferentes recursos indiciadores de sentido, novos gêneros discursivos. Essas questões ampliam as exigências para o ensino de língua portuguesa, que precisa contemplar o trabalho com textos multimodais/multissemióticos, nas suas realizações verbais (fala e escrita) e não verbais (sons, imagens, gestos etc), uma vez que a prática da escrita não se consubstancia apenas pela modalidade verbal. Essas novas configurações convocam novos letramentos, uma vez que contemplam usos sociais da linguagem que configuram os enunciados/textos em sua multissemiose (multiplicidade de semioses ou linguagens), ou multimodalidade. 
Assim, analisar a inter-relação entre os diferentes recursos constitutivos dos diversos gêneros discursivos - concretizados em suas diferentes estruturas composicionais, em seus suportes, em suas funções comunicativas, com seus estilos de linguagem - é essencial para uma adequada percepção de como as combinações dos modos semióticos criam significado a fim de alcançar os propósitos definidos em cada prática social.

Por meio da análise empreendida, foi possível constatar que uma proposta de produção de textos em sala de aula que contempla as diferentes semioses constitutivas dos textos, observando-se os conhecimentos prévios dos alunos e as suas capacidades de aprendizagem, pode favorecer a formação de sujeitos para fazer uso crítico das informações em ambiente digital. Constatou-se que a percepção e a criação de com-

Quem conta um conto aumenta um ponto posições imagéticas são demandas da escola e da sociedade, uma vez que os gêneros discursivos que circulam socialmente exigem níveis de compreensão e análise mais aprofundados e sistemáticos do funcionamento das diferentes linguagens, para ampliar suas possibilidades de aprender, de atuar socialmente e de explicar e interpretar criticamente os atos de linguagem. A consideração das relações estabelecidas entre os elementos constitutivos e da produção dos sentidos permite um enfrentamento da complexidade inerente ao processo de organização dos textos multissemióticos que circulam socialmente, viabilizando a formação de um produtor de texto mais crítico, mais propositivo e mais criativo.

Para além dessas questões, o trabalho empreendido, por sua constituição dialógica - diálogos entre vários autores e perspectivas teóricas - evidencia que a reflexão sobre a produção de textos, em uma perspectiva dos multiletramentos, demanda a construção de um posicionamento epistemológico e axiológico que sustente o processo de ensino-aprendizagem e propicie a ressignificação das interações nele instauradas. 


\section{REFERÊNCIAS}

Helena Maria

Ferreira

Marco Antonio

Villarta-Neder

Geanne dos

Santos Cabral

Coe

152

ANTUNES, I. Aula de português: encontro \& interação. São Paulo, SP: Parábola, 2003.

BAKHTIN, M. M. Os gêneros do discurso. Tradução do russo, organização, posfácio e notas de Paulo Bezerra. São Paulo: Editora 34, 2016, 176p.

BAKHTIN, M. M. Questões de Estilística no ensino da língua. Tradução do russo, posfácio e notas de Sheila Camargo Grillo e Ekaterina Vólkova Américo. São Paulo: Editora 34, 2013, 232 p.

BALTAR, M. A competência discursiva através dos gêneros textuais: uma experiência com o jornal de sala de aula. 139 p. Tese (Doutorado em Letras) - Universidade Federal do Rio Grande do Sul, 2003.

BERTGES, L. R.; PEREIRA, V. C. Uma proposta de análise intersemiótica do gênero GIF poema partir de "Asas" e "Volve", de Arnaldo Antunes. Desenredo. Revista do PPGL da Universidade de Passo Fundo - v. 13 - n. 2 - p. 492-507 - maio/ago. 2017. Disponível em <seer.upf. br/index.php/rd/article/download/7250/4461> Acesso em 12 maio 2018.

BRAIT, B. PCNs, gêneros e ensino de língua: faces discursivas da textualidade. In: ROJO, R. (Org.). A prática de linguagem na sala de aula. Praticando os PCNs. São Paulo: Mercado Aberto, 2002.

BUNZEN, C. Jr. Da era da composição à era dos gêneros: um ensino de produção de textos no ensino médio. In: BUNZEN, C; MENDONÇA, M. Português no ensino médio e formação do professor. São Paulo: Parábola, 2007.

CASTALDO, Márcia Martins. Redação no vestibular: a língua cindida. 2009. 277 f. Tese (doutorado). Faculdade de Educação, Universidade de São Paulo, 2009.

CUSTÓDIO, M. A. Documentário e pichação: a escrita na rua como produção multissemiótica. In: ROJO, R. H. R; MOURA. E. Multiletramentos na escola. 2. ed. São Paulo: Parábola Editorial, 2016. 
DIAS, A. V. M. Hipercontos multissemióticos: para a promoção dos multiletramentos. In: ROJO, R. H. R; MOURA. E. Multiletramentos na escola. 2. ed. São Paulo: Parábola Editorial, 2016.

DIONÍSIO, A. P.; VASCONCELOS, L. J. Multimodalidade, gênero textual e leitura. In: BUNZEN, C; MENDONÇA, M. Múltiplas linguagens para o ensino médio. São Paulo: Parábola, 2013.

DUDENEY, G; HOCKLY, N.; PEGRUM, M. Letramentos digitais. Trad. Marcos Marcionilo. São Paulo: Parábola, 2016. 352 p.

Quem conta um conto aumenta um ponto

FERREIRA, H.; VILLARTA-NEDER, M. A. Textualização e Enunciação Vida. Prolíngua. v. 12, n. 2- out/dez de 2017.

GARCIA, C. B.; SILVA, F. D. S.; FELÍCIO, R. P. Projet(o) arte: uma proposta didática. In: ROJO, R. H. R; MOURA. E. Multiletramentos na escola. 2. ed. São Paulo: Parábola, 2016.

GERALDI, J. W. Portos de Passagem. 4. ed. São Paulo: Martins Fontes, 2003. p. 115- 165.

GUEDES, P. C. Da redação à produção textual: o ensino da escrita. 2. ed. São Paulo: Parábola Editorial, 2012.

JOLY, M. Introdução à Análise da Imagem. Lisboa: Edições 70, 2007.

LANKSHEAR, C.; KNOBEL, M. Sampling the new in new literacies. In: . (orgs.) A new literacies sampler. Nova York: Peter Lang, 2007.

MATÊNCIO, M .L. M. Referenciação e retextualização de textos acadêmicos: um estudo do resumo e da resenha. In: III Congresso Internacional da Abralin. 2003, Rio de Janeiro. Anais... Rio de Janeiro: Universidade Federal do Rio de Janeiro, 2003.

ORLANDI, E. P. Nem escritor, nem sujeito: apenas autor. In: Discurso e leitura. Ática: São Paulo, 1988. p. 75-83. 
OTTONI, M. A. R. Os gêneros do humor no ensino da língua portuguesa: uma abordagem discursiva crítica. 2007. 399 f. Tese (Doutorado em

Helena Maria

Ferreira

Marco Antonio

Villarta-Neder

Geanne dos

Santos Cabral

Coe

154
Linguística) - Universidade de Brasília, Brasília, 2007.

PÉCORA, A. Problemas de redação. São Paulo: Martins Fontes, 1986.

PIMENTA, S. M. O.; SANTANA A. C. D. A. Multimodalidade e semiótica social: o estado da arte. In: MATTE A. C. F. (org.). Lingua(gem), texto, discurso: entre a reflexão e a prática. Rio de janeiro: Lucerna: Belo Horizonte, MG: FALE/UFMG, 2007, v. 2, p. $152-174$.

PINTON, F. M.; GONÇALVES, A. C. T. O ensino de produção textual em diferentes perspectivas teóricas. Universidade Federal da Fronteira Sul (UFFS), 2012.

RESENDE, A P. de S., CANO, M. R. de O. O discurso hiperbólico no processo de construção da violência no jornal. Kiri-kerê: Pesquisa em Ensino, n. 2, maio 2017. P. 112- 136. Disponível em: < http:// periodicos.ufes.br/kirikere/article/view/15723/11518 >. Acesso em 10 abr. 2018.

ROJO, R. H. Por novos e múltiplos letramentos. Na Ponta do Lápis. ano XII, n. 27, p. 6 - 11, 2016. Disponível em: < https://www.escrevendoofuturo.org.br/arquivos/5917/npl27-03ago2016.pdf>. Acesso em: 10 jun. 2018. (entrevista).

ROJO, R. H.; BARBOSA, J. Hipermodernidade, multiletramentos e gêneros discursivos. São Paulo: Parábola, 2017.

ROJO, R. H.; CORDEIRO, G.S. Apresentação: Gêneros orais e escritos como objetos de ensino: modo de pensar, modo de fazer. In: $\mathrm{SCH}-$ NEUWLY, B.; DOLZ, J. Gêneros orais e escritos na escola. 3. ed. Campinas, SP: Mercado de Letras, 2011.

ROJO, R.H. Protótipos didáticos para os multiletramentos. In: ROJO, R. H. R; MOURA. E. Multiletramentos na escola. São Paulo: Parábola Editorial, 2009. 
STREET, B.V. Multiletramentos. In: FRADE, I. C. A.; COSTA VAL, M. da G; BREGUNCI, M. G. de C. (orgs.). Glossário Ceale on-line: termos de alfabetização, leitura e escrita para educadores. Belo Horizonte: UFMG/Faculdade de Educação, 2014, s/p. Disponível em: < http:// www.ceale.fae.ufmg.br/app/webroot/glossarioceale/verbetes/multimodalidade>. Acesso em: 2 dez. 2017.

TEIXEIRA, D. O.; MOURA, E. Chapeuzinho vermelho: por uma educaQuem conta ção linguística com multiletramentos. In: ROJO, R. H. R; MOURA. E. um conto Multiletramentos na escola. 2. ed. São Paulo: Parábola Editorial, 2016. aumenta um ponto

VIEIRA, E. A. P.; SILVA, F. D. S.; ALENCAR, M. C. M. A canção roda-vida: da leitura às leituras. In: ROJO, R. H. R; MOURA. E. Multiletramentos na escola. 2. ed. São Paulo: Parábola Editorial, 2016. 
